a. Vehicles

b. EMS equipment

2. Victim transport rates

3. Mean transport times: critical versus non-critical victims

E. Preparation for International Assistance

F. Study Design Problems

V. Conclusion

A. Significant Mean Transport Times between Critical versus Non-critical Victims

B. Other Areas of Concern

Keywords: assistance; communications; cooperation, earthquakes; Guatemala; injury patterns; interagency; interventions; military; outcomes; resources; response; transport times; triage

Prebosp Disast Med 2002;17(s2):s69-70.

TIVA Remifentanil and TCI Propofol Anaesthesia Alisher Agzamov; A.M. Al Qattan; A.Y. Doubikitis; Hani A. Al Qattan

Department of Anaesthesiology \& ICU, Al Sabah Hospital, Kuwait City, Kuwait

Objective: This study was designed to investigate the differences between total intravenous anaesthesia (TIVA) of remifentanil and target controlled infusion (TCI) of propofol and balanced anaesthesia with isoflurane/fentanyl in abdominal laparoscopic surgery. Emphasis was placed on haemodynamic reaction, BIS Index monitoring, recovery profile, postoperative side effects, and patient satisfaction. Methods: Two hundred twenty patients were assigned randomly to receive either total intravenous anaesthesia with TIVA remifentanil/TCI propofol or balanced anaesthesia with isoflurane/fentanyl. After premedication (atropine, pethidine, and midazolam), and induction of anaesthesia (TCI propofol, cisatracurium) in both groups, either 1 microgram $/ \mathrm{kg}$ fentanyl (Group I) or 1 microgram $/ \mathrm{kg} / \mathrm{min}$ TIVA remifentanil for induction; then 0.05-0.5 microgram $/ \mathrm{kg} / \mathrm{min}$ (Group II) was given. Anaesthesia was maintained with $0.05-0.5$ microgram $/ \mathrm{kg} / \mathrm{min}$ TIVA remifentanil (Group II) and 3.5-6.5 microgram $/ \mathrm{ml} \mathrm{TCI} \mathrm{propofol} \mathrm{or} 1.5 \mathrm{vol} \%$ isoflurane (Group I). Both groups were ventilated mechanically with $50 \%$ oxygen in air. The administration of isoflurane and the infusion of the anaesthetics were adjusted to maintain a surgical depth of anaesthesia with BIS Monitor (42 \pm 6.6 in Group I and $44 \pm 7.2$ in Group II). For postoperative analgesia, $20 \mathrm{mg}$ pethidine was administered intravenously $5-10$ min before the end of surgery for propofol/remifentanil group anaesthesia patients. After recovery, $0.25-0.50 \mathrm{mg} / \mathrm{kg}$ pethidine was given intravenously to both group patients. At the end of surgery, the anaesthetics were discontinued and haemodynamics, early emergence from anaesthesia, pain level, frequency of analgesic demand, incidence of PONV, shivering, and patient satisfaction were assessed. Parameters were recorded for 24 hours postoperatively.

Results: Recovery time after TIVA remifentanil/TCI propofol anaesthesia for Group II patients was significantly $(p<0.05)$ shorter than for Group I patients after administration of isoflurane and fentanyl: (1) Spontaneous ventilation, 3.0 vs. $7.0 \mathrm{~min}$; (2) Extubation, 4.5 vs. $9.0 \mathrm{~min}$; (3) Eye opening, 4.0 vs $8.2 \mathrm{~min}$; (4) Stating name, 5.5 vs. 13.0 $\min$; and (5) stating date of birth, 0.0 vs. $15.0 \mathrm{~min}$ ). There were no significant differences between the groups in shivering, pain score, analgesic demand, and PONV. The Group I patients responded to tracheal intubation with significantly higher blood pressure than the Group II.

During maintenance of anaesthesia, heart rate in patients in Group I was significantly higher (Group II: HR $\max +11 /-10$; Group I: HR $\max +23 /-0$.); Measured on a scale (Group I: 65\%).

Conclusion: Compared with patients given standard, balanced anaesthesia with isoflurane and fentanyl, total intravenous anaesthesia with TCI propofol and TIVA remifentanil proved to be particularly suited for abdominal laparoscopic surgery. Its major advantages are haemodynamic stability, significantly shorter times of emergence, and the exceptional acceptance by the patients.

Keywords: anesthesia; fentanyl; haemodynamics; isoflurane; propofol; recovery; remifenanil; surgery, laparoscopic abdominal; target controlled infusion (TCI); total intravenous anaesthesia (TIVA)

Prehosp Disast Med 2002;17(s2):s70.

\section{An Earthquake Disaster In Turkey: An Overview of the Israeli Defence Forces Field Hospital in Duzce - November 1999}

Yaron Bar-Dayan, $M D, M H A, ;^{1,3}$ Pinar Beard, $M D ;^{2}$

David Mankuta, $M D ;^{1}$ Dan Engelhart, $M D ;^{1}$ Yftah Beer,

$M D ;^{1}$ Mauryzio Lynn, MD; ${ }^{1}$ Yuval Weiss, $M D, M H A ;{ }^{1}$

Giora Martonovits, $M D, M P S c, M P A,{ }^{1}$ Paul Benedek,

$M D, M H A ;{ }^{1}$ Avishay Goldberg, $P h D, M P H, M A^{3}$

1. Israeli Defence Forces Medical Corps Mission Team Field Hospital in Adapazari, Israel

2. Turkish medical volunteer

3. Department of Health Management, the Faculty of Medicine, Ben-Gurion University, Israel

On 12 November 1999 at 22:00, a recurrent earthquake of 7.2 magnitude (Richter scale) struck Turkey three months after a previous earthquake disaster in the same region. This time, Turkey had suffered 705 fatalities and approximately 3,500 injured. The earthquake significantly damaged the infrastructure of the cities, including that of the health system. This time the damage was more localized than in the previous earthquake of August. Medical teams and rescue services from numerous countries were posted in the region and provided medical aid.

The IDF Field Hospital arrived at Duzce on day 3 after the quake. The team consisted of 100 personnel. The field hospital acted as a secondary referral center to the primary care clinics in Duzce, to several worldwide volunteering medical teams, and to the partially functioning three hospitals of Duzce. The IDF field hospital provided an operating theater and hospitalization facilities in the damaged city, whereas the local hospitals could not provide these services in the first two weeks after the quake. An outpatient clinic based on local medical volunteer personnel was functioning in the field hospital from day 5 .

A total of 2,230 patients were treated in the field hospital between day 3 and day 11 of the earthquake. The frequency distribution of the medical problems seen in the field hospital was $37 \%$ pediatric diseases, $32 \%$ internal medicine, $21 \%$ general, orthopedic, and plastic surgery, and $10 \%$ obstetrics and gynecology. A total of 84 patients 